\title{
BMJ Introduction effects of the Australian open plain packaging policy on adult smokers: a cross-sectional study
}

\author{
Melanie A Wakefield, Linda Hayes, Sarah Durkin, Ron Borland
}

To cite: Wakefield MA, Hayes L, Durkin S, et al. Introduction effects of the Australian plain packaging policy on adult smokers: a cross-sectional study. BMJ Open 2013;3:e003175. doi:10.1136/bmjopen-2013003175

- Prepublication history for this paper is available online. To view these files please visit the journal online (http://dx.doi.org/10.1136/ bmjopen-2013-003175).

Received 8 May 2013 Revised 4 June 2013 Accepted 12 June 2013

This final article is available for use under the terms of the Creative Commons Attribution Non-Commercial 3.0 Licence; see http://bmjopen.bmj.com

Centre for Behavioural Research in Cancer, Cancer Council Victoria, Carlton, Victoria, Australia

\section{Correspondence to}

Prof Melanie Wakefield; melanie.wakefield@cancervic. org.au

\begin{abstract}
Objective: To determine whether smokers smoking from packs required under Australia's plain packaging law had different smoking beliefs and quitting thoughts, compared with those still smoking from branded packs. Design: Cross-sectional survey during the roll-out phase of the law, analysed by timing of survey.

Setting: Australian state of Victoria, November 2012. Participants: 536 cigarette smokers with a usual brand, of whom $72.3 \%$ were smoking from a plain pack and $27.7 \%$ were smoking from a branded pack.

Primary outcome measures: Perceived quality and satisfaction of cigarettes compared with 1 year ago, frequency of thoughts of smoking harm, perceived exaggeration of harms, frequency of thoughts of quitting, quitting priority in life, intention to quit, approval of large graphic health warnings and plain packaging.
\end{abstract}

Results: Compared with branded pack smokers, those smoking from plain packs perceived their cigarettes to be lower in quality (adjusted OR (AdjOR)=1.66, $p=0.045$ ), tended to perceive their cigarettes as less satisfying than a year ago (AdjOR=1.70, $p=0.052$ ), were more likely to have thought about quitting at least once a day in the past week (AdjOR=1.81, $\mathrm{p}=0.013$ ) and to rate quitting as a higher priority in their lives $(F=13.11$, $d f=1, p<0.001$ ). Plain pack smokers were more likely to support the policy than branded pack smokers (AdjOR=1.51, $p=0.049$ ). Branded and plain pack smokers did not differ on measures of less immediate smoking intentions, frequency of thoughts about harms or perceived exaggeration of harms. Appeal outcomes, but not other outcomes, were sensitive to the extent of roll-out, with responses from branded pack smokers approaching those of plain pack smokers, once $80 \%$ of survey respondents were smoking from plain packs 12 weeks before the December implementation date.

Conclusions: The early indication is that plain packaging is associated with lower smoking appeal, more support for the policy and more urgency to quit among adult smokers.

\section{INTRODUCTION}

From 1 September 2012, all tobacco manufactured for sale in Australia was required to be contained in plain dark brown packs, with

\section{ARTICLE SUMMARY}

Article focus

- Past studies have demonstrated that plain, as opposed to branded, tobacco packaging leads smokers to perceive the packs as lower in appeal, to make health warnings more salient and to reduce misapprehensions about the perceived harms of smoking.

- Since no country had implemented plain packaging prior to Australia, all the studies conducted to date have simulated plain packaging.

- We examined the early impact of plain packaging on smokers in vivo as policy implementation rolled out for the first time in Australia in late 2012 in respect of the perceived appeal and harm outcomes and, in addition, examined any potential effects on thoughts of quitting.

\section{Key messages}

- Compared with smokers smoking from branded packs, smokers who were smoking from the new plain packs were more likely to perceive their tobacco as being lower in quality and tended to be lower in satisfaction, were more likely to think about and prioritise quitting, and more likely to support the plain packaging policy.

- Appeal outcomes, but not other outcomes, were sensitive to the extent to which plain packaging had rolled out among the smoker population over the survey period, with responses from branded pack smokers approaching those of plain pack smokers, at a time when $80 \%$ of the survey respondents were smoking from plain packs $1-2$ weeks before the December implementation date.

$75 \%$ front-of-pack graphic health warnings and the brand name and variant limited to a standardised font size and type. ${ }^{1}$ This requirement supplanted Australian legislation that had required 30\% front-of-pack graphic health warnings since 2006. ${ }^{2}$ The new plain packs with larger warnings began appearing for sale at retail outlets early in October and increasingly so during November, since from 1 December 2012, all tobacco sold at retail outlets was required to be contained in plain packs. The roll-out period of the new packs 


\section{ARTICLE SUMMARY}

Strengths and limitations of this study

- The study used a representative population survey of smokers and was timed to occur over the period of introduction of plain packs into the Australian market.

- Although multivariate analysis adjusted for the underlying differences between plain and branded pack smokers, these results may be partly explained by differential selection, with some smokers choosing to avoid the new plain packs for as long as possible.

- Some smokers of branded packs may previously have smoked from a plain pack, which would be expected to reduce differences between plain and branded pack smokers.

- Our study is not able to tease apart the independent contributions of plain packaging and the new larger graphic-health warnings, since they co-occurred.

was accompanied by a nationally televised mass media campaign throughout November, promoting several serious harms of smoking that were also featured on the larger pack health warnings, including blindness, lung cancer and pregnancy-related harm. Other health warnings featured in the larger pack health warnings were peripheral vascular disease (gangrene), mouth (tongue) cancer and improvements to health from quitting.

Plain packaging aims to reduce the attractiveness and appeal of tobacco, increase the noticeability and effectiveness of health warnings and reduce the ability of packaging to mislead consumers about smoking harms. ${ }^{1}$ While the legislation is expected to exert effects on smoking behaviour indirectly through achievement of the above objectives, and in the long term as part of a comprehensive suite of measures, there is also interest in examining any short-run effects on adult smokers. As part of an annual population survey of adults conducted throughout November and early December 2012, we examined the attitudes and intentions of smokers during this roll-out period, comparing those who were smoking cigarettes from the new plain packs with larger health warnings, with those still smoking from a branded pack with smaller warnings.

\section{METHOD}

\section{Study design and participants}

The Victorian Smoking and Health Survey is a crosssectional telephone survey undertaken annually with a representative sample of adults aged 18 years and over, residing in the general population of the Australian state of Victoria. Fieldwork for the 2012 survey occurred between 1 November and 3 December inclusive.

Computer-assisted telephone interviews were conducted using a dual frame survey design incorporating samples generated by Random Digit Dialling (RDD) to landline and mobile phones. In $45 \%$ of cases where it was possible to match landline phone numbers to residential addresses, primary approach letters were posted prior to the phone call to give notice of a 'community survey of health attitudes and behaviours'. As Australian mobile phone numbers have no geographic identifier, it was not possible to send approach letters to potential participants contacted through RDD to mobile phones. A helpline number was provided to all participants as a means of verifying the survey or obtaining further information.

After establishing contact with a verified landline sample number, up to nine call attempts were made to complete an interview. Calls to unanswered mobile phones were limited to four attempts. When calling a landline phone, interviewers asked to speak to the youngest male aged 18 years or over at home at the time of the call. If no men were available, the youngest adult woman in the household was selected to participate. Within the mobile RDD sample, the individual answering a call was considered to be the target for screening. A quota was applied to the landline sample to ensure that approximately $70 \%$ of interviews were conducted with metropolitan residents and $30 \%$ with rural residents, reflecting the population distribution of Victoria. Given the absence of geographic identifiers for the mobile numbers, no quota was applied to the mobile sample and state of residence was established on contact.

In total, 3126 landline and 878 mobile phone interviews were completed. Interviews were conducted in English only. Verbal consent was obtained from participants at the start of each interview. The overall response rate, defined as completed interviews as a proportion of the sample who could be contacted within the call cycle and who were identified as eligible for the survey, was $63 \%$.

Ethics approval to undertake the survey was obtained from Cancer Council Victoria's Human Research Ethics Committee (HREC: 0018).

\section{Measures}

All questions were asked within the context of a broader 12 min population survey of attitudes and behaviours relating to smoking. Smokers were identified as individuals who currently smoked cigarettes, pipes and/or cigars daily, weekly or less than weekly. After being further asked about the types of tobacco currently consumed, current cigarette smokers were those who smoked factory-made cigarettes (FMC) or roll-your-own (RYO) cigarettes daily, weekly or less than weekly. All cigarette smokers were asked to specify their usual brand. Based on price class definitions listed in the grocery trade magazine Retail World, ${ }^{3}$ brands were classified into three segments (value, mainstream or premium). Where a brand was not listed, price per stick was used to determine the most appropriate classification, based on the thresholds used in Retail World. All RYO cigarette smokers $(n=35)$ were assigned to the value market segment.

To ascertain exposure to the new plain packs, current cigarette smokers who reported smoking their usual FMC or RYO brand were asked: "Is the cigarette/ tobacco pack you are currently smoking one of the new 
dark brown packs which has all of its logos removed and a large picture health warning on the front?"

To assess brand appeal, all current smokers were asked: "I'm going to read some statements about how you rate your current cigarettes compared to a year ago. I'd like you to tell me if you think that now, your cigarettes are higher, lower or about the same in terms of ...' a) 'Quality?' b) 'Satisfaction?" To assess perceived harm, smokers were asked: "In the last week how often, if at all, did you think about the harm your smoking might be doing to you?" with response options being 'never', 'rarely', 'sometimes', 'often' and 'very often' (and aggregated for analysis into 'often or very often' vs all others) and: "Would you agree or disagree that the dangers of smoking have been exaggerated?" with response options from strongly agree, agree, neither, disagree and strongly disagree.

To examine quitting thoughts and intentions, smokers were asked: "Are you seriously considering quitting smoking in the next 6 months?"; "Are you planning to quit smoking in the next 30 days?" and "On a scale of 1 to 10 , where 1 is lowest and 10 is highest, how would you rate quitting as a priority in your life?" Quitting salience was measured with the question: "During the past week, how often have you thought about quitting?" with responses ranging from 'not at all' to 'several times a day'. Responses were aggregated for analysis into 'once a day or more often' versus 'less often or not at all'.

Opinion about the new health warnings was determined by asking: "In order to strengthen the impact of the health messages on packs, the Federal government requires that from December 1 2012, the size of graphic health warnings will be increased to cover $75 \%$ of the front of the cigarette pack. Do you support or oppose increasing the size of graphic health warnings to $75 \%$ of the front of the cigarette pack?" The responses of smokers who 'strongly' or 'somewhat' supported the enlarged graphic health warnings were compared with the responses of those who opposed or had no opinion about the size increase. Plain packaging opinions were assessed by asking: "Tobacco companies often use cigarette packaging for promotional purposes. Because of this, the Federal government requires that from December 1 2012, cigarettes will be sold in plain packaging. This will mean that the packs will all look the same with the logos and colours removed. Just the brand in plain text and the graphic health warnings will remain on the packs. Do you approve or disapprove of this?" Respondents who reported that they approved or strongly approved were compared with others.

The average number of cigarettes smoked each day was calculated for daily and weekly smokers based on their self-reported consumption. For the purposes of analyses, less than weekly smokers were classified in the lowest consumption group ( $<5$ cigarettes/day). Smokers who had never attempted to quit were compared with smokers who had made at least one previous quit attempt, based on responses to the question:
"Approximately how many times, if any, have you tried to give up smoking?"

During the fieldwork period, three antismoking advertisements were broadcast on television as part of a national antismoking mass media campaign. Respondents were read a short description of each advertisement and smokers who recalled seeing at least one were compared with those who did not recall any advertisements.

Respondents were classified into three socioeconomic status (SES) groups using the Index of Relative Disadvantage (IRSD), ${ }^{4}$ which ranks postal areas on a continuum of high-to-low disadvantage, taking into consideration characteristics including income, education, occupation and housing. The low SES (high disadvantage) group comprised people in the bottom $40 \%$ of ranked postal areas; the mid SES group included people who lived in areas with an IRSD score between $41 \%$ and $80 \%$ of ranked postal areas, while the high SES (lowest disadvantage) group lived in areas with an IRSD score between $81 \%$ and $100 \%$ of ranked postal areas.

\section{Statistical analyses}

All data were weighted by age and gender, based on the 2011 Australian census. ${ }^{5}$ Data weights also accounted for a participant's relative chance of inclusion in the landline or mobile phone sample frame, and their chance of selection based on the number of landlines in each household and number of in-scope people per household.

We first compared the characteristics of those smoking from plain and branded packs using bivariate logistic regression for binary variables and analysis of variance for continuous outcomes. Variables associated with plain or branded pack use at $\mathrm{p}<0.25$ were included as covariates in multivariate logistic regression analyses, following Hosmer and Lemeshow, ${ }^{6}$ to examine whether current possession of a plain pack compared with a branded pack was associated with brand appeal, perceived harm, quitting thoughts and intentions, and support for packaging legislation and in analysis of covariance to determine if smoking from a plain pack was associated with higher ratings of quitting as a life priority.

A third set of models additionally controlled for the proportion of the sample interviewed during each survey week who reported smoking from a plain pack. We did this to control for the extent to which, as the survey period progressed, smokers would have been increasingly exposed to plain packs in their social networks, even though they may not have been personally smoking from one. Finally, in a sensitivity analysis, we repeated all analyses for brand loyal smokers, defined as those who had been smoking the same brand for a year.

\section{RESULTS}

\section{Participant characteristics}

Of the total of 4004 interviews, 572 current cigarette smokers were identified. Of these, nine reported that they did not smoke a usual brand, 13 did not know or 
refused to say what their usual brand was and two reported smoking unbranded cigarettes. (Unbranded tobacco is untaxed loose tobacco without any branding, sold in unmarked plastic bags.) A further 10 smokers did not know if they were currently smoking from a plain pack and two indicated that they did not currently possess a pack, leaving 536 current FMC or RYO smokers with a usual brand who indicated that they were smoking from a plain or branded pack. Although the interviewers had scope to record if smokers responded that they had transferred their cigarettes into a case, no smokers reported having done so.

Table 1 shows the characteristics of 536 usual brand cigarette smokers who were smoking from a plain pack $(72.3 \% \mathrm{n}=388)$ or a branded pack $(27.7 \%, \mathrm{n}=148)$. The proportion of usual brand cigarette smokers who were smoking from a plain pack increased from $57.2 \%$ in the first week of surveying to $85 \%$ in the final week.

\section{Bivariate comparison of those smoking from branded and plain packs}

Smokers currently smoking from a plain pack did not differ from smokers who were currently smoking from a branded pack with respect to age, sex, education or area of residence (table 2). Smokers were significantly more likely to be smoking from a plain pack if they lived in a medium compared with a low socioeconomic area $(\mathrm{OR}=1.55, \mathrm{p}=.050)$, or reported having ever made a quit attempt $(\mathrm{OR}=2.61, \mathrm{p}<0.001)$ and there was a trend towards being more likely to smoke from a plain pack if they recalled having seen recent antismoking campaign advertising on television $(\mathrm{OR}=1.45, \mathrm{p}=0.056)$. Compared with smokers of value brands, smokers of mainstream $(\mathrm{OR}=2.38, \mathrm{p}<0.001)$ and premium $(\mathrm{OR}=1.80, \mathrm{p}=0.021)$ brands were also more likely to currently be smoking from a plain pack. Compared with those who smoked fewer than five cigarettes/day, smokers of between 5 and 10 cigarettes a day $(\mathrm{OR}=1.57, \mathrm{p}=0.098)$ tended to be more likely to be smoking from a plain pack. As a result of these analyses, SES, recall of recent antismoking television advertisements, brand segment, cigarette consumption and having ever made a quit attempt were included as covariates in multivariate models.

\section{Multivariate comparison of those smoking from branded and plain packs}

After adjusting for covariates (table 3, model 1), plain pack smokers were more likely than branded pack smokers to perceive their cigarettes to be of lower quality than a year ago $(\mathrm{OR}=1.66, \mathrm{p}=0.045)$, and trended towards perceiving their cigarettes to be less satisfying than a year ago $(\mathrm{OR}=1.70, \mathrm{p}=0.052)$. Plain pack smokers were slightly but not significantly more likely than branded pack smokers to have thought about the harms of smoking 'often' or 'very often' in the previous week (adjusted OR (AdjOR)=1.43, $\mathrm{p}=0.115)$, but did not differ in belief that the dangers of smoking had been exaggerated.

\begin{tabular}{|c|c|c|}
\hline & Number* & $\begin{array}{l}\text { Per } \\
\text { cent }\end{array}$ \\
\hline Total & 536 & 100 \\
\hline \multicolumn{3}{|l|}{ Sex } \\
\hline Male & 303 & 56.6 \\
\hline Female & 233 & 43.4 \\
\hline \multicolumn{3}{|l|}{ Age group (years) } \\
\hline $18-29$ & 163 & 30.4 \\
\hline $30-49$ & 229 & 42.8 \\
\hline $50+$ & 144 & 26.8 \\
\hline \multicolumn{3}{|l|}{ Education } \\
\hline Up to year 12 & 333 & 62.0 \\
\hline Tertiary level and above & 204 & 38.0 \\
\hline \multicolumn{3}{|l|}{ Socioeconomic status } \\
\hline Low (most disadvantaged) & 129 & 24.1 \\
\hline Medium & 345 & 64.2 \\
\hline High (least disadvantaged) & 63 & 11.7 \\
\hline \multicolumn{3}{|l|}{ Area of residence } \\
\hline Metropolitan Victoria & 387 & 72.1 \\
\hline Regional Victoria & 146 & 27.2 \\
\hline Unknown & 4 & 0.7 \\
\hline \multicolumn{3}{|l|}{$\begin{array}{l}\text { Current daily consumption level } \\
\text { (average no of cigarettes/day) }\end{array}$} \\
\hline$<5$ (includes non-daily smokers) & 139 & 25.8 \\
\hline$>5-10$ & 132 & 24.6 \\
\hline$>10-15$ & 103 & 19.2 \\
\hline$>15$ & 150 & 28.0 \\
\hline Unknown & 13 & 2.4 \\
\hline \multicolumn{3}{|l|}{ Ever tried to quit } \\
\hline No & 86 & 16.0 \\
\hline Yes & 446 & 83.2 \\
\hline Unknown & 4 & 0.8 \\
\hline \multicolumn{3}{|l|}{ Brand segment } \\
\hline Value & 140 & 26.2 \\
\hline Mainstream & 249 & 46.4 \\
\hline Premium & 147 & 27.4 \\
\hline \multicolumn{3}{|c|}{ Exposure to antismoking TV campaign } \\
\hline Did not recall any advertisements & 243 & 45.3 \\
\hline $\begin{array}{l}\text { Recalled at least one antismoking } \\
\text { advertisement }\end{array}$ & 293 & 54.7 \\
\hline \multicolumn{3}{|l|}{ Smoking from a plain pack } \\
\hline Week 1 & 125 & 57.2 \\
\hline Week 2 & 142 & 66.3 \\
\hline Week 3 & 142 & 80.4 \\
\hline Weeks 4-5 & 126 & 85.0 \\
\hline
\end{tabular}

${ }^{*}$ Numbers may not add to $\mathrm{N}=536$ due to rounding off of weighted numbers.

Smokers with a plain pack rated quitting as being a significantly higher priority in their life (mean=6.76) compared with those who were smoking from branded packs (mean=5.62; adjusted $\mathrm{F}=13.11, \mathrm{df}=1, \mathrm{p}<0.001$ ). Smokers who were currently smoking from a plain pack were almost twice as likely to report that they had thought about quitting at least once a day over the past week (AdjOR=1.81, $\mathrm{p}=0.013$ ) when compared with smokers of branded packs. No differences between plain and branded pack smokers were found for quit intentions within 30 days or the next 6 months. 
Table 2 Characteristics of cigarette smokers currently smoking from a plain pack compared with a branded pack

\begin{tabular}{|c|c|c|c|}
\hline & $\begin{array}{l}\mathrm{N} \text { smoking from a } \\
\text { plain pack }\end{array}$ & $\begin{array}{l}\text { Percentage of smoking } \\
\text { from a plain pack }\end{array}$ & $\begin{array}{l}\text { Unadjusted OR } \\
(95 \% \mathrm{Cl})\end{array}$ \\
\hline Total $(\mathrm{N}=536)$ & 388 & 72.3 & \\
\hline \multicolumn{4}{|l|}{ Sex } \\
\hline Male $(n=303)$ & 214 & 70.4 & 1.00 (Ref) \\
\hline Female $(n=233)$ & 174 & 74.8 & OR 1.25 (0.85 to 1.83$), p=0.262$ \\
\hline Age group (years) & & & $p=0.579$ \\
\hline $18-29(n=163)$ & 123 & 75.2 & 1.00 (Ref) \\
\hline $30-49(n=229)$ & 164 & 71.6 & $\mathrm{OR}=0.83(0.53$ to 1.32$), p=0.432$ \\
\hline $50+(n=144)$ & 101 & 70.1 & $\mathrm{OR}=0.77(0.47$ to 1.28$), p=0.317$ \\
\hline \multicolumn{4}{|l|}{ Education } \\
\hline Up to year $12(n=333)$ & 235 & 70.6 & 1.00 (Ref) \\
\hline Tertiary level and above $(n=204)$ & 153 & 75.1 & $\mathrm{OR}=1.26(0.85$ to 1.87$), p=0.258$ \\
\hline Socioeconomic status & & & $p=0.150$ \\
\hline Low $(n=129)$ & 85 & 65.6 & 1.00 (Ref) \\
\hline Medium $(n=345)$ & 257 & 74.7 & $\mathrm{OR}=1.55(1.00$ to 2.40$), p=0.050$ \\
\hline High $(n=63)$ & 46 & 73.1 & $\mathrm{OR}=1.42(0.73$ to 2.77$), p=0.299$ \\
\hline \multicolumn{4}{|l|}{ Area of residence $(n=532)$} \\
\hline Metropolitan Victoria $(\mathrm{n}=387)$ & 279 & 72.1 & 1.00 (Ref) \\
\hline Regional Victoria $(n=146)$ & 105 & 72.2 & $\mathrm{OR}=1.00(0.66$ to 1.53$), p=0.990$ \\
\hline $\begin{array}{l}\text { Current daily consumption level } \\
\text { (average no of cigarettes/day } n=523 \text { ) }\end{array}$ & & & $\mathrm{p}=0.312$ \\
\hline$<5$ (including non-daily smokers) $(n=139)$ & 92 & 66.3 & 1.00 \\
\hline$>5-10 \quad(n=132)$ & 100 & 75.5 & $\mathrm{OR}=1.57$ (0.92 to 2.66$), p=0.098$ \\
\hline$>10-15(n=103)$ & 78 & 75.3 & $\mathrm{OR}=1.55(0.88$ to 2.74$), p=0.133$ \\
\hline$>15(n=150)$ & 107 & 71.2 & $\mathrm{OR}=1.26(0.76$ to 2.07$), p=0.370$ \\
\hline \multicolumn{4}{|l|}{ Ever tried to quit $(n=532)$} \\
\hline No $(n=86)$ & 46 & 54.2 & 1.00 (Ref) \\
\hline Yes $(n=446)$ & 337 & 75.6 & $\mathrm{OR}=2.61(1.62$ to 4.21$), \mathrm{p}<0.001$ \\
\hline Brand segment & & & $p=0.001$ \\
\hline Value $(n=140)$ & 85 & 60.4 & 1.00 (Ref) \\
\hline Mainstream $(n=249)$ & 195 & 78.4 & $\mathrm{OR}=2.38(1.51$ to 3.74$), \mathrm{p}<0.001$ \\
\hline Premium $(n=147)$ & 108 & 73.3 & $\mathrm{OR}=1.80$ (1.09 to 2.96$), p=0.021$ \\
\hline \multicolumn{4}{|l|}{ Exposure to antismoking TV campaign } \\
\hline Did not recall advertising $(n=243)$ & 166 & 68.3 & 1.00 (Ref) \\
\hline $\begin{array}{l}\text { Recalled at least one of three antismoking } \\
\text { campaign advertisements }(n=293)\end{array}$ & 222 & 75.7 & $\mathrm{OR}=1.45(0.99$ to 2.12$), \mathrm{p}=0.056$ \\
\hline
\end{tabular}

Plain and branded pack smokers did not differ in terms of their support for increasing the size of graphic health warnings, but a greater proportion of plain pack smokers approved of plain packaging than branded pack smokers (AdjOR=1.51, $\mathrm{p}=0.049$ ).

Additional covariate adjustment for the proportion of the sample smoking from a plain pack (table 3, model 2) resulted in no material change in effect sizes or statistical significance for all outcomes, except for the appeal outcomes. For the measures of quality and satisfaction, this adjustment resulted in a slight reduction in effect sizes, with differences no longer being statistically significant. Figure 1 shows that early in the survey period when the overall proportion of the sample smoking from plain packs was lower, a greater proportion of plain pack smokers thought their cigarettes were lower in quality and satisfaction than did the branded pack smokers. As the roll-out of plain packs reached $80 \%$ or more of smokers surveyed in the third week of
November (1-2 weeks before the December implementation date), the responses of branded pack smokers approached those of plain pack smokers.

\section{Brand loyal cigarette smokers}

Of the 536 usual brand cigarette smokers, 452 indicated that they had been smoking their current brand for 1 year or longer. (We excluded smokers who said that they had been smoking their current brand for less than a year $(\mathrm{n}=60)$ or who did not give a time period $(n=23)$.) We found that $30 \%$ of the 329 plain pack smokers and $20.1 \%$ of the 123 branded pack smokers thought that the quality of their cigarettes was lower than a year ago (AdjOR=1.54, $\mathrm{p}=0.108$ ), and $25.1 \%$ of plain pack smokers and $16.2 \%$ of branded pack smokers thought that their satisfaction was lower than a year ago $(\mathrm{OR}=1.57, \mathrm{p}=0.122)$. Thus, effect sizes eased slightly and significance levels declined. Again, once adjustment was undertaken for the proportion of participants smoking 
Table 3 Attitudes and intentions of respondents who were currently smoking from a plain pack compared with those respondents who were smoking from a branded pack $^{*}$

\begin{tabular}{|c|c|c|c|c|c|}
\hline & $\begin{array}{l}\text { Smoking from a } \\
\text { plain pack }(n=388)\end{array}$ & $\begin{array}{l}\text { Smoking from a } \\
\text { branded pack }(n=148)\end{array}$ & $\begin{array}{l}\text { Unadjusted OR } \\
(95 \% \mathrm{Cl}), \mathrm{p} \text { value }\end{array}$ & $\begin{array}{l}\text { Model 1: adjusted OR† } \\
(95 \% \mathrm{Cl}), \mathrm{p} \text { value }\end{array}$ & $\begin{array}{l}\text { Model 2: adjusted OR } \\
(95 \% \mathrm{Cl}), \mathrm{p} \text { value }\end{array}$ \\
\hline Brand appeal & $\mathrm{N}(\%)$ & $\mathrm{N}(\%)$ & & & \\
\hline Brand quality: Lower than a year ago & $119(30.6)$ & $27(18.1)$ & $\begin{array}{l}\mathrm{OR}=2.00(1.25 \text { to } \\
3.20) p=0.004\end{array}$ & $\begin{array}{l}\text { OR=1.66 (1.01 to } 2.72) \\
p=0.045\end{array}$ & $\begin{array}{l}\text { OR=1.41 (0.85 to } 2.35) \\
p=0.187\end{array}$ \\
\hline $\begin{array}{l}\text { Brand satisfaction: Lower than a year } \\
\text { ago }\end{array}$ & $102(26.2)$ & $22(14.9)$ & $\begin{array}{l}\mathrm{OR}=2.03(1.22 \text { to } \\
3.36) \mathrm{p}=0.006\end{array}$ & $\begin{array}{l}\text { OR=1.70 (1.00 to } 2.89) \\
p=0.052\end{array}$ & $\begin{array}{l}\text { OR }=1.53(0.88 \text { to } 2.63) \\
p=0.130\end{array}$ \\
\hline Perceived harm & $\mathrm{N}(\%)$ & $\mathrm{N}(\%)$ & & & \\
\hline $\begin{array}{l}\text { Thought about the harms of smoking } \\
\text { 'often' or 'very often' in the last week }\end{array}$ & $178(45.9)$ & $53(35.6)$ & $\begin{array}{l}\mathrm{OR}=1.56(1.04 \text { to } \\
2.36) \mathrm{p}=0.032\end{array}$ & $\begin{array}{l}\text { OR }=1.43(0.92 \text { to } 2.22) \\
p=0.115\end{array}$ & $\begin{array}{l}\text { OR }=1.42(0.90 \text { to } 2.24) \\
p=0.129\end{array}$ \\
\hline $\begin{array}{l}\text { Believe the dangers of smoking have } \\
\text { been exaggerated }\end{array}$ & $125(32.3)$ & $46(30.9)$ & $\begin{array}{l}O R=1.07(0.71 \text { to } \\
1.61) p=0.753\end{array}$ & $\begin{array}{l}O R=1.15(0.75 \text { to } 1.78) \\
p=0.526\end{array}$ & $\begin{array}{l}\mathrm{OR}=1.15(0.73 \text { to } 1.80) \\
\mathrm{p}=0.551\end{array}$ \\
\hline Quitting thoughts and intentions & Mean (SD), N & Mean (SD), N & $\begin{array}{l}\text { Unadjusted } F, d f, \\
\text { p value }\end{array}$ & Adjusted F†, df, p value & Adjusted F $\neq$, df, $p$ value \\
\hline \multirow[t]{2}{*}{$\begin{array}{l}\text { Quitting as a priority in my life }{ }^{\star *} \\
\text { (0 lowest to } 10 \text { highest) }\end{array}$} & $6.76(2.85), 337$ & 5.62 (2.99), 130 & $\begin{array}{l}F=14.76, d f=1,464 \\
p<0.001\end{array}$ & $\begin{array}{l}F=13.11, d f=1,442 \\
p<0.000\end{array}$ & $\begin{array}{l}F=11.25, d f=1,441 \\
p=0.001\end{array}$ \\
\hline & $N(\%)$ & $\mathrm{N}(\%)$ & & & \\
\hline $\begin{array}{l}\text { Thought about quitting at least once a } \\
\text { day in the last week }\end{array}$ & $143(36.8)$ & $32(21.8)$ & $\begin{array}{l}\mathrm{OR}=2.09(1.35 \text { to } \\
3.25) \mathrm{p}=0.001\end{array}$ & $\begin{array}{l}\text { OR=1.81 (1.13 to } 2.89) \\
p=0.013\end{array}$ & $\begin{array}{l}\text { OR }=1.82(1.13 \text { to } 2.95) \\
p=0.014\end{array}$ \\
\hline Planning to quit in the next 30 days & $100(25.8)$ & $27(18.1)$ & $\begin{array}{l}O R=1.58(0.98 \text { to } \\
2.54) p=0.060\end{array}$ & $\begin{array}{l}\mathrm{OR}=1.31(0.78 \text { to } 2.18) \\
\mathrm{p}=0.309\end{array}$ & $\begin{array}{l}\text { OR }=1.28(0.75 \text { to } 2.17) \\
p=.363\end{array}$ \\
\hline $\begin{array}{l}\text { Seriously considering quitting in the } \\
\text { next } 6 \text { months }\end{array}$ & $267(68.8)$ & $85(57.1)$ & $\begin{array}{l}O R=1.66(1.12 \text { to } \\
2.45) p=0.011\end{array}$ & $\begin{array}{l}\mathrm{OR}=1.30(0.85 \text { to } 1.98) \\
p=0.221\end{array}$ & $\begin{array}{l}\mathrm{OR}=1.34(0.86 \text { to } 2.07) \\
p=0.195\end{array}$ \\
\hline Support for the new legislation & $\mathrm{N}(\%)$ & $\mathrm{N}(\%)$ & & & \\
\hline $\begin{array}{l}\text { Support for an increase in graphic } \\
\text { health warning size to } 75 \% \text { front of } \\
\text { pack }\end{array}$ & $211(54.4)$ & $79(53.5)$ & $\begin{array}{l}\mathrm{OR}=1.04(0.71 \text { to } \\
1.52) \mathrm{p}=0.841\end{array}$ & $\begin{array}{l}\mathrm{OR}=0.97(0.64 \text { to } 1.46) \\
p=0.882\end{array}$ & $\begin{array}{l}\text { OR=1.01 (0.66 to } 1.55) \\
p=0.955\end{array}$ \\
\hline $\begin{array}{l}\text { Approval for the introduction of plain } \\
\text { packaging }\end{array}$ & $203(52.4)$ & $63(42.2)$ & $\begin{array}{l}\mathrm{OR}=1.51(1.03 \text { to } \\
2.21) \mathrm{p}=0.034\end{array}$ & $\begin{array}{l}\text { OR=1.51 (1.00 to } 2.28) \\
p=0.049\end{array}$ & $\begin{array}{l}\text { OR=1.63 (1.07 to } 2.49) \\
p=0.024\end{array}$ \\
\hline
\end{tabular}

*Numbers may not add to $\mathrm{N}=536$ due to rounding off of weighted numbers.

†Adjusted for SES, daily consumption levels, recalled at least one anti-smoking advertisement, brand segment and previous quit attempts.

$\ddagger$ Also adjusted for covariates, and proportion of sample smoking from a plain pack each week of the interview.

${ }^{* *}$ Due to skip error in questionnaire only asked of current smokers aged under 60 years.

SES, socioeconomic status. 
Figure 1 Appeal outcomes by survey week for plain and branded pack smokers.

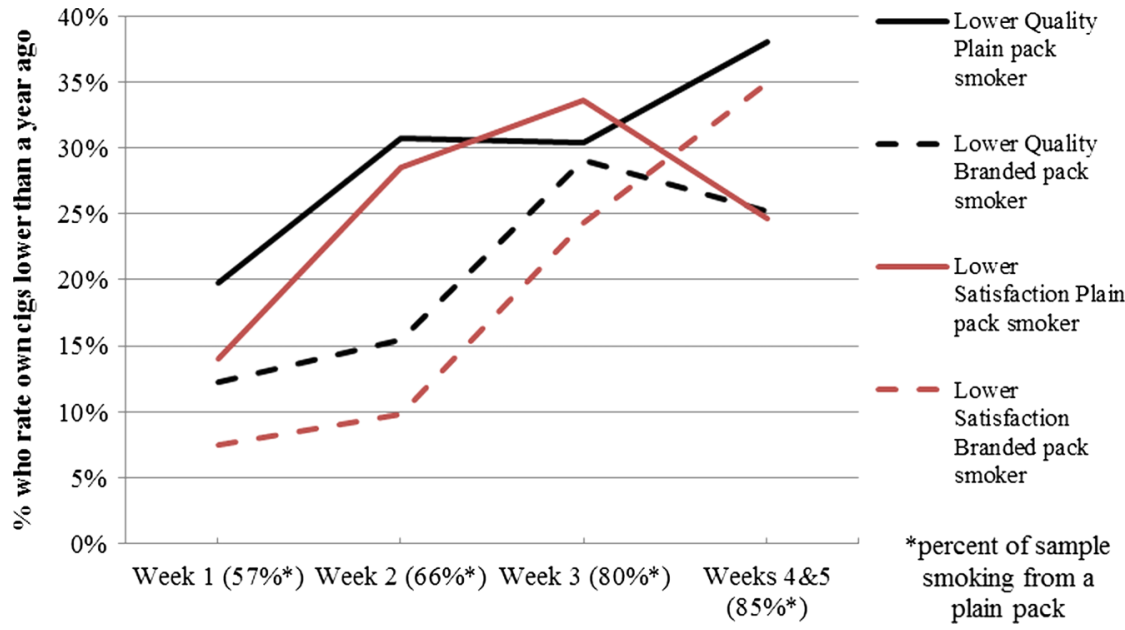

from a plain pack during each survey week, the effect sizes diminished further (lower quality $\mathrm{OR}=1.32, \mathrm{p}=.318$; lower satisfaction $\mathrm{OR}=1.36, \mathrm{p}=0.307$ ), but remained in the same direction. The strength and pattern of findings for all other outcomes remained the same as the main analysis.

\section{DISCUSSION}

Compared with branded pack smokers, smokers who were smoking from plain packs rated their cigarettes as being lower in quality and as tending to be less satisfying than 1 year ago. These appeal outcomes were sensitive to the extent to which plain packaging had rolled out among the smoker population over the survey period, with responses from branded pack smokers approaching those of plain pack smokers, once $80 \%$ of survey respondents were smoking from plain packs 1-2 weeks before the December implementation date. Among brand loyal smokers, effects were in the same direction but not significant. In all analyses, plain pack smokers were more likely to think often or very often about quitting in the past week and to rate quitting as a higher priority in their lives, compared with branded pack smokers. There were no significant differences in the proportion of plain and branded pack smokers who thought frequently about the harms of smoking or thought smoking harms had been exaggerated. While a similar proportion of plain and branded pack smokers supported the larger graphic health warnings, a significantly greater proportion of plain pack smokers approved of plain packaging.

Given that Australia is the first nation to implement plain packaging, our study provides an early investigation of its actual effects on smokers in a market where plain packs are available to all, compared with past studies that have experimentally exposed smokers to a single viewing of a plain or branded pack which may or may not have been their own brand, ${ }^{7-13}$ and naturalistic studies that have mocked-up plain packs for smokers to carry around with them in a trial situation. ${ }^{14} 15$
In the period leading up to the 1 December implementation date, plain packs began to be sold at retail from early October and the timing of our survey enabled a comparison of those who were smoking from one of the new plain packs with those who were not. Our survey obviously excludes the responses of those who may have quit during this short period. Our designation of smokers as plain or branded was based on the pack from which they were currently smoking at the time of survey administration. It should not be assumed that those smoking from branded packs had not previously purchased and smoked from a plain pack. Indeed, this would have been increasingly likely as the survey period progressed and, even if branded pack smokers had not themselves purchased a plain pack, they would have been increasingly exposed to them via their social networks.

Our study demonstrated that responses for branded pack smokers began to approach those of plain pack smokers for the two appeal outcomes towards the end of the survey period. This could mean that having around $80 \%$ of smokers smoking from a plain pack represents a threshold of availability for social contagion effects, or it may reflect a point where the likelihood of not having smoked from a plain pack was approaching zero, and thus all responses were influenced by having smoked cigarettes from plain packs.

Smoking from a plain pack as compared with a branded pack could be due to differences in availability or to choice. Differences across the survey week are clearly due to the increased availability of plain packs and reduced availability of branded packs. In addition, brand segment and SES differences in the likelihood of smoking from a plain pack could be due to the differential availability of plain packs by brand or residential area. The higher rate of recall of the mass media campaign among those with plain packs might be due to the accompanying large pack health warnings assisting the memorability or impact of the television messages, as has been found in past studies. ${ }^{16}{ }^{17}$ However, the difference observed in past quitting behaviour between those with plain and branded packs is more consistent with 
differential choice. Although we adjusted for ever having previously tried to quit, there may have been residual confounding, so that those less interested in quitting may have been more likely to avoid the plain packs. Avoidance of plain packs by these smokers would be entirely consistent with the notion that plain packs make smokers feel uncomfortable about their smoking, as found in two naturalistic studies. ${ }^{14}{ }^{15}$ Some of the relationships found between pack type and quitting outcomes could be due to those more interested in quitting being less likely to avoid or even to seek out the plain packs. However, even if this is the case, the net effect of plain packaging for quitting remains positive.

The observed pattern of findings in relation to brand appeal and the direction of findings relating to perceived harms is consistent with those of experimental studies of plain packaging conducted in Australia, ${ }^{78}$ the $\mathrm{UK}^{8}{ }^{19}$ and other countries ${ }^{11-132021}$ and also with the Australian government's pretesting of mocked-up plain packs. ${ }^{22}$ The finding that smokers smoking from a plain pack evidenced more frequent thoughts about and priority for quitting than branded pack smokers is important, since frequency of thoughts about quitting has strong predictive validity in prospective studies for actually making a quit attempt. ${ }^{23} 24$ Past research on graphic health warnings has found that the larger size of warnings is associated with more message recall, greater perceived effectiveness and risks of smoking ${ }^{25}{ }^{26}$ and less appeal. ${ }^{27}$ Also, noticing pictorial health warnings on others' tobacco packs reduced the risk of relapse in recent quitters in a cohort study. ${ }^{28}$ Our study is not able to tease apart the independent contributions of plain packaging and the new larger health warnings, since they co-occurred. These responses are unlikely to be due to any media campaign effects since we adjusted for campaign recall and, in other analyses, determined that campaign recall was unrelated to the frequency of thoughts of harm and quitting intentions and importance.

We noted that the proportion who thought the harms had been exaggerated was not higher for plain pack smokers with the larger graphic warnings, than for branded pack smokers. We also found similar proportions of branded and plain pack smokers who supported the larger graphic health warnings, with a majority supporting it. Interestingly, those smoking from plain packs were more likely to approve of plain packaging than those smoking from branded packs. Given that $73 \%$ of Australian smokers intend to quit ${ }^{29}$ and over $90 \%$ regret having started, ${ }^{30}$ smokers may acknowledge such packaging changes as a source of motivation or reminder for quitting, and/or as being important to reduce the appeal of smoking for young people. This pattern of differences in approval is similar to the pattern of increase in public support that is observed when smoke-free laws ${ }^{31} 32$ and display bans ${ }^{33}$ have been implemented.

We note that the initial responses observed in this study concur with the news reports during November and December of smokers perceiving their cigarettes 'taste worse ${ }^{, 34}{ }^{35}$-an effect likely to be attributable to the halo effects of packaging influencing the sensory experience of smoking ${ }^{36}$ - and with reports of increases in calls to Quitlines. ${ }^{37}$ Overall, the introductory effects we observed are consistent with the broad objectives of the plain packaging legislation. We await further research to examine more durable effects on smokers and any effects on youth.

Contributors MAW and LH conceived the study. MAW, LH and RB designed the survey questions. LH and SD undertook data analysis, MAW and LH drafted the manuscript and SD and RB revised the content. All authors approved the final submitted version. MAW is the study guarantor.

Funding This study was funded by Quit Victoria. The researchers declare that they are independent from the funder. The funder had no influence on the overall study design or on the decision to submit the paper for publication.

Competing interest LH and SD had financial support from Quit Victoria for the submitted work.

Ethics approval Ethical approval for the study was provided by the Human Research Ethics Committee of Cancer Council Victoria (HREC 0018).

Provenance and peer review Not commissioned; externally peer reviewed.

Data sharing statement No additional data are available.

\section{REFERENCES}

1. Tobacco Plain Packaging Act 2011. Australia: Commonwealth of Australia, 2011. http://www.austlii.edu.au/au/legis/cth/num_act/ tppa2011180/ (accessed 5 July 2013).

2. Australian Government. Trade Practices (Consumer Product Information Standards) (Tobacco) Regulations 2004. Canberra, Australia, 2007.

3. Retail World. Annual report: Market sizes and shares. 2011.

4. Australian Bureau of Statistics. Information paper: an introduction to socio-economic indexes for areas (SEIFA) 2006. Canberra, Australia: Australian Bureau of Statistics, 2008:Catalogue no. 2039.0.

5. Australian Institute of Health and Welfare. National health data dictionary. Version 8.0. AlHW Catalogue No. HWI 18. Canberra, Australia: Australian Institute of Health and Welfare, 1999.

6. Hosmer DW, Lemeshow S. Applied logistic regression analysis. 2 edn. Wiley Series in probability and statistics, 2000.

7. Wakefield M, Germain D, Durkin S. How does increasingly plainer cigarette packaging influence adult smokers' perceptions about brand image? An experimental study. Tob Control 2008;17:416-21.

8. Hammond D, Dockrell M, Arnott D, et al. Cigarette pack design and perceptions of risk among UK adults and youth. Eur J Public Health 2009;19:631-7.

9. Hammond D, Parkinson $C$. The impact of cigarette package design on perceptions of risk. J Public Health 2009;31:345-53.

10. Doxey J, Hammond D. Deadly in pink: the impact of cigarette packaging among young women. Tob Control 2011;20:353-60.

11. Thrasher JF, Rousu MC, Hammond D, et al. Estimating the impact of pictorial health warnings and "plain" cigarette packaging: evidence from experimental auctions among adult smokers in the United States. Health Policy 2011;102:41-8.

12. Gallopel-Morvan K, Moodie C, Hammond D, et al. Consumer perceptions of cigarette pack design in France: a comparison of regular, limited edition and plain packaging. Tob Control 2012;21:502-6.

13. Scheffels J, Saebo G. Perceptions of plain and branded cigarette packaging among norwegian youth and adults: a Focus Group Study. Nicotine Tob Res 2013;15:450-6.

14. Moodie C, Mackintosh AM, Hastings G, et al. Young adult smokers' perceptions of plain packaging: a pilot naturalistic study. Tob Control 2011;20:367-73.

15. Moodie CS, Mackintosh AM. Young adult women smokers' response to using plain cigarette packaging: a naturalistic approach. $B M J$ Open 2013;3:e002402.

16. Brennan E, Durkin S, Cotter T, et al. Mass media campaigns designed to support new pictorial health warnings on cigarette packets: evidence of a complementary relationship. Tob Control 2011;20:412-18.

17. Thrasher JF, Murukutla N, Perez-Hernandez R, et al. Linking mass media campaigns to pictorial warning labels on cigarette packages: a cross-sectional study to evaluate effects among Mexican smokers. Tob Control 2013;22:e57-65. 
18. Borland R, Savvas S, Sharkie F, et al. The impact of structural packaging design on young adult smokers' perceptions of tobacco products. Tob Control 2013;22:97-102.

19. Moodie C, Ford A, Mackintosh AM, et al. Young people's perceptions of cigarette packaging and plain packaging: an online survey. Nicotine Tob Res 2012;14:98-105.

20. Hammond D, Doxey J, Daniel S, et al. Impact of female-oriented cigarette packaging in the United States. Nicotine Tob Res 2011:13:579-88.

21. Moodie C, Stead M, Bauld L, et al. Plain tobacco packaging: a systematic review. Stirling, Scotland: University of Stirling, 2012.

22. GfK bluemoon. Market research to determine impact of plain packaging on other tobacco products, 2011.

23. Borland $\mathrm{R}$, Yong $\mathrm{HH}$, Wilson $\mathrm{N}$, et al. How reactions to cigarette packet health warnings influence quitting: findings from the ITC Four-Country survey. Addiction 2009;104:669-75.

24. Borland R, Wilson N, Fong GT, et al. Impact of graphic and text warnings on cigarette packs: findings from four countries over five years. Tob Control 2009;18:358-64.

25. Shanahan P, Elliott D. Evaluation of the effectiveness of the graphic health warnings on tobacco product packaging 2008. Canberra, Australia: Australian Government Department of Health and Ageing, 2009.

26. Hammond D. Health warning messages on tobacco products: a review. Tob Control 2011;20:327-37.

27. Hoek J, Wong C, Gendall P, et al. Effects of dissuasive packaging on young adult smokers. Tob Control 2011;20:183-8.

28. Partos TR, Borland R, Yong HH, et al. Cigarette packet warning labels can prevent relapse: findings from the International
Tobacco Control 4-Country policy evaluation cohort study. Tob Control 2013;22:e43-50.

29. Cooper J, Borland R, Yong HH. Australian smokers increasingly use help to quit, but number of attempts remains stable: findings from the International Tobacco Control Study 2002-09. Aust N Z J Public Health 2011;35:368-76.

30. Fong GT, Hammond D, Laux FL, et al. The near-universal experience of regret among smokers in four countries: findings from the International Tobacco Control Policy Evaluation Survey. Nicotine Tob Res 2004;6(Suppl 3):341-51.

31. Hyland A, Higbee C, Borland R, et al. Attitudes and beliefs about secondhand smoke and smoke-free policies in four countries: findings from the International Tobacco Control Four Country Survey. Nicotine Tob Res 2009;11:642-9.

32. Cooper J, Borland $\mathrm{R}$, Yong $\mathrm{HH}$, et al. Compliance and support for bans on smoking in licensed venues in Australia: findings from the International Tobacco Control Four-Country Survey. Aust N Z J Public Health 2010;34:379-85.

33. McNeill A, Lewis S, Quinn C, et al. Evaluation of the removal of point-of-sale tobacco displays in Ireland. Tob Control 2011;20:137-43.

34. Dunlevy S, Stark P. Plain packaging leaves bad taste in smokers mouths. Herald Sun 30 November 2012

35. Hagan K, Harrison D. Plain packs 'put off' smokers. The Age 30 November 2012.

36. Wakefield M. Welcome to Cardboard Country: how plain packaging could change the subjective experience of smoking. [Invited editorial]. Tob Control 2011;20:321-2.

37. Sharkie F. Time to come clean on hazards of smoking. Herald Sun 29 December 2012. 